\title{
Mini review of carbon based additive in machining lubricant
}

\author{
K. Jun Li', A.A. Radhiyah ${ }^{1}$ \\ ${ }^{1}$ Faculty of Manufacturing and Mechatronic Engineering Technology, Universiti Malaysia Pahang, 26600 Pahang, Malaysia.
}

\begin{abstract}
Milling process is a major machining process used in various type of industries. This process is used to manufacture components such as impellers and structural parts in aerospace industry. Several problems can be arising during the machining operation because $99 \%$ of work done produces heat to the chip, the tool and also the workpiece. The temperature of the tool may rise up to $1000^{\circ} \mathrm{C}$ and this could lead to accelerate the tool wear rate and also the finishing of the surface of the workpiece. In order to improvise this phenomenon, various type of cutting fluid is used in milling operation to use to reduce the temperature of the workpiece. In general, the fluids are used when cutting the workpiece to lower the heat generated at the interface of the tool chip and also the friction on the workpiece. There are four main types of cutting fluid when commonly found in the market which is straight oils, synthetic fluids, soluble oils and the semi-synthetic fluids. This paper is reviewing on the additive for lubricant and their tribology properties.
\end{abstract}

ARTICLE HISTORY

Revised: $30^{\text {th }}$ September 2020

Accepted: $30^{\text {th }}$ September 2020

\section{KEYWORDS}

Carbon based additive

Machining lubricant

Milling

\section{INTRODUCTION}

Carbon $(\mathrm{C})$ is a nonmetallic element grouped in Group 14 in the periodic table. Carbon is distributed wide in the nature, but it is not particular plentiful. It only contains 0.032 percent in the Earth's crust yet more compounds are formed than all the other. The isotope of carbon, carbon-12 is the standard relative to measure the atomic weights of the other elements. Carbon itself can form a strong single bond that is stable enough to withstand chemical attack in ambient conditions.

As a free element, carbon has a lot of uses in the market, including jewelry such as diamonds or black fume pigment in automobile's rims and the printer's ink. Carbon itself can appear in another form as graphite. Graphite is use as crucible that can withstand high temperature, electrodes in dry cell and light arch, and the pencil lead. Carbon can also appear in amorphous form that called as vegetal carbon, used as gas absorbent and bleaching agent.

Carbon can be activated using a various type of activation agent. Activated carbons are among the most used adsorbents[1]. They possess a great variety of modified surface groups, making them useful in water purification, as gas removers, and in the recovery of materials, etc. [1]The global consumption of activated carbons was 750,000 $\mathrm{t}$ in 2002. The estimated growth of worldwide demand is $4-5 \%$ per year, with higher growth rates of 5-6\% per year projected for the U.S. between 2002 and 2005[1].

Currently, activated carbon are manufactured by different kind of raw material such as agriculture residue[2], coconut shell, waste sugarcane bagasse[3], corn cob[4], different types of wood, nutshell and coal. With the additive of activated carbon into the base lubricant, it can help to make an improvement on the life of the machine elements and reduce the energy losses while performing machining operation[5].

\section{REVIEW ON CARBON BASED ADDITIVE IN LUBRICANT}

\section{Addlitive in lubricant}

Basically, adding additive into lubricant is one of the method to reduce the frictional resistance in machining application [6]. There are several types of additive which are currently using in the industry to improve the lubricant performance of the bas oil [5]. The nanoparticles that usually use ad additive are $\mathrm{Al}_{2} \mathrm{O}_{3}, \mathrm{CuO}, \mathrm{TiO}_{2}, \mathrm{ZnO}$, graphene and others. These nanoparticles have the following characteristic such as low wear scar diameter, high viscosity, high pressure distribution, high load carrying capacity and low friction coefficient [5]. According to Xie, additive play an important role in improving lubricants behaviour during cutting process [7]. Activated carbon can also be use as additive in lubricant to improve the properties of the lubricant and improve the surface roughness of the cutting fluid [7], [8]. 
Nanofluid used in lubricant application

\begin{tabular}{lccccc}
\hline Nanoparticle & Base fluid & Size $(\mathbf{n m})$ & $\begin{array}{l}\text { Wear } \\
\text { reduction } \\
(\%)\end{array}$ & $\begin{array}{c}\text { Friction } \\
\text { reduction } \\
(\%)\end{array}$ & Concentration \\
\hline $\mathrm{CuO}$ & $\mathrm{GO}, \mathrm{PAO}$ & 40 & & 45 & $0.005-2 \mathrm{vol} \%$ \\
Graphene & $\mathrm{LO}$ & 500 & $20-68$ & $40-70$ & $0.001-30 \mathrm{wt} \%$ \\
Graphite & $\mathrm{LO}$ & 500 & & $1-30 \mathrm{wt} \%$ \\
$\mathrm{CNT} \mathrm{MWNT}$, fullerene, diamond & $\mathrm{EO}, \mathrm{GO}$ & 200 & $40-50$ & $10-55$ & $0.001-30 \mathrm{wt} \%$ \\
$\mathrm{BN} \mathrm{h-BN}$ & $\mathrm{PAO}, \mathrm{GO}$ & 150 & 15 & 20 & $1 \mathrm{wt} \%$ \\
$\mathrm{TiO}_{2}, \mathrm{Al}_{2} \mathrm{O}_{3}, \mathrm{SiO}_{2}, \mathrm{MoO}_{2}$ & $\mathrm{LO}, \mathrm{EO}$ & $40-100$ & & & $0.01-10 \mathrm{wt} \%$ \\
\hline
\end{tabular}

GO=gear oil; $L O=$ lubricant oil; $E O=$ engine oil; $P A O=$ polyalphaolefine

Source: [9]

\section{Activated carbon based lubricant}

Activated carbon is an organic matter that is highly porous which can be applied in plenty of industries. For examples, they often being used as catalysts, adsorbents and catalyst support[2]. According to International Union of Pure and Applied Chemistry (IUPAC), activated carbon is defined as a porous carbon material which can react with gases and chemical before, during or after the activation process in order to improve the adsorptive properties [10]. The wellstructured porous structure and surface chemical functionalities strengthen the interaction between polar and non-polar adhesion [10]. Normally, the pore size volume is range from $0.20-0.60 \mathrm{~cm}^{3} / \mathrm{g}$, surface area range from $800-1500 \mathrm{~m}^{2} / \mathrm{g}$ and the pore diameter is smaller than 2nm (Leimkuehler, 2010). Due to its large surface area, high total pore volume, strong mechanical strength and stability in chemical properties, the demand over the world is estimated to rise around $6 \%$ per year and the figure will reach 2.0 million metric tons by the year 2025 [12]. The application of the activated carbon can be applied in water purification, VOC recovery, garbage incineration, catalytic deodorizer, removal of siloxane in digestive gas and acid rain protection [13].

The porous structure of activated carbon is one of the major reasons that researchers use it as additive in lubricant. According to the research from Meiling, additive off activated carbon in lubricant for 1 wt $\%$ shows a remarkable improvement during the experiment. The friction coefficient decreased by $25.7 \%$ and the wear resistance increased by 3.21 times when the weight ration of activated carbon additive is $10 \%$ [14]. The carbon additive is working out like a spacer. This is to prevent the asperities of two metal surface from mating each other [15].

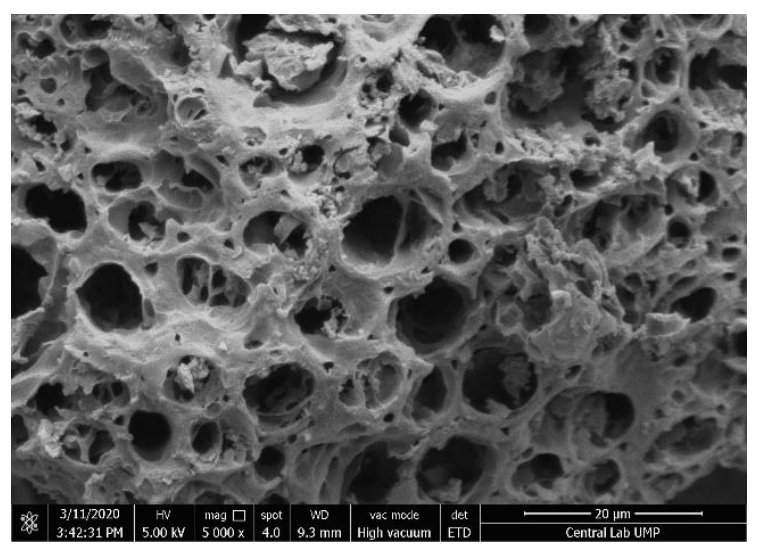

Figure 1. Activated carbon

\section{Preparation of activated carbon}

Basically, the main purpose of activation process is to increase the pore volume, enhance the pore volume and enlarge the pore diameter [16]. Any material with high carbon content and low inorganic, can be used as the raw material such as forest, agriculture and municipal wastes, lignite, petroleum pitch, coal and lignocellulosic biomass to produce activated carbon [10]. Besides, different precursors of vegetables type such as oils, husks, pits and seeds from plants and fruits and polymeric materials can be used to produce activated carbon. Because of the low cost and renewable source, agricultural 
residues have the advantages to be chosen as the precursors for production of activated carbon[17]. A general method for preparing activated carbon has been proposed by Thomas with the use of natural resources.

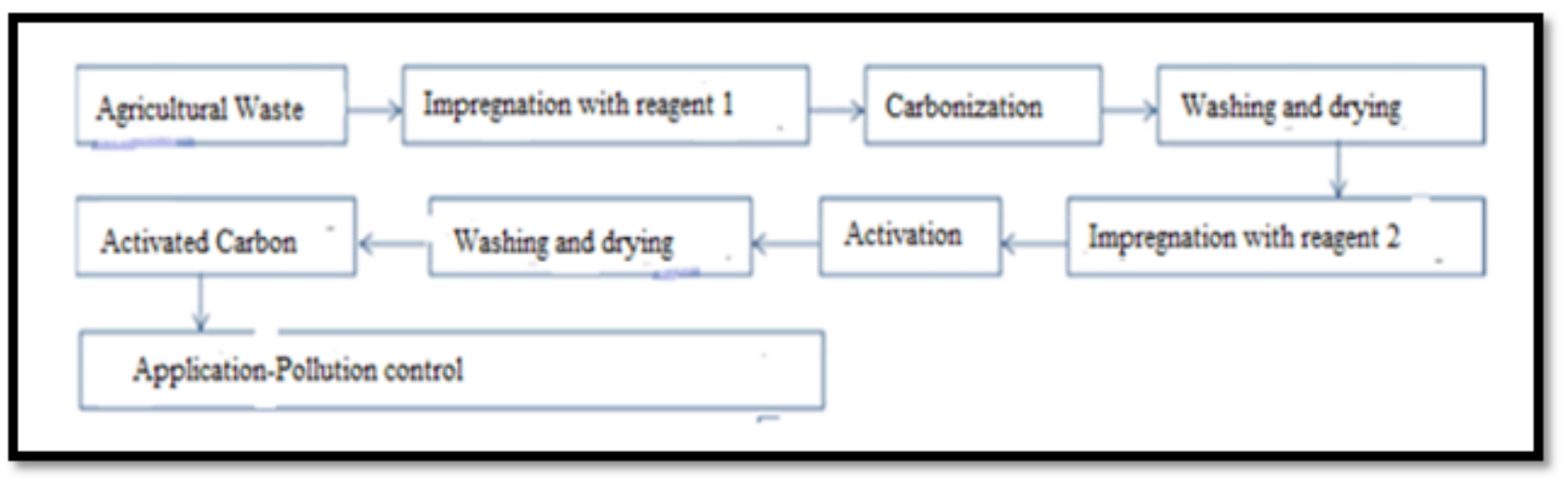

Figure 2. A general method of preparation of activated carbon from natural resources [13].

\section{Graphene based lubricant}

Graphene is a six-carbon atom lied in a layer showing a honeycomb lattice in hexagonal shape. Graphene present itself as a two-dimensional(2D) structure in a single layer [18].Besides, graphene shows a good mechanical strength, smooth atomic surface, excellent thermal stability and low surface energy. With promising the low surface energy, adhesion and friction on different substrate can be reduced [18]. Furthermore, due to its low interlayer shear strength and the layer structure, graphene were actively being used in research for the tribology properties [19]. According to the research, the nanoparticles from graphene family able to make a separation from the contact and form a protective film on the interface of the frictional and possess a special antiwear function. This results in improving the lubricating performance for the base lubricant [19].

\begin{tabular}{ll}
\hline & Properties of graphene [18] \\
\hline Properties & \multicolumn{1}{c}{ Values } \\
\hline Thermal conductivity & $\sim 2600 \mathrm{~W} \mathrm{~m}^{-1} \mathrm{~K}^{-1}$ \\
Specific surface area & $\sim 4125 \mathrm{~K}$ (predicted) \\
Melting point & $0.142 \mathrm{~nm}$ \\
C-C bond strength & 0.335 \\
Interplanar spacing between graphene sheets & $\sim 1 \mathrm{TPa}\left(1.5 \mathrm{x}^{-1} 0^{8} \mathrm{psi}\right)$ \\
Young's modulus & $\sim 130 \mathrm{Gpa}^{-13}$ \\
Tensile strength & $\sim 4 \mathrm{Mpa} \mathrm{m}^{1 / 2}$ \\
Fracture toughness & $\sim 200,000 \mathrm{~cm}^{2} \mathrm{~V}^{-1} \mathrm{~s}^{-1}$ \\
Electron mobility & $2 \times 10^{11} \mathrm{~cm}^{-2}$ \\
Electron density & \\
\hline
\end{tabular}

Additive of graphene into base lubricant can improve the anti-friction and anti-wear properties. Graphene can improve the lubricating condition by providing a nano-bearing effect that form a protective tribolayer. In the hole of the textured surface, graphene nanoparticle can be stored and released [18]. According to the research carried out by Mohamed, the tribological result shows that graphene nanolubricant had improve the anti-friction properties by $29-35 \%$ and the antiwear properties by 22-29\% during a boundary lubricating system[20]. For solid lubricant, graphene nanosheet also shows a compromising result. For a tribological test carried out in air, a stable and compact sliding interface between graphene nanosheet is observed [21]. 


\section{Carbon nanotube based lubricant}

Carbon nanotube is a single layer of carbon atom (graphene) rolled up in the form of sheet. It can be categorised into 2 groups which is single-walled (SWCNT) with the diameter less than 1 nanometre and multi-walled (MWCNT) which contain of few interlinked nanotubes concentrically. The size is in micrometres or millimetres. According to Leander's research, MWCNT shows its ability in reducing friction and wear for various type of operations. For instances, environmental roughness, surface pressure, temperature and humidity [22]. Besides, the viscosity index of CNT is investigated by Hadi. The researchers found out that the viscosity index of the lubricant increase by adding CNT into the base lubricant [23].
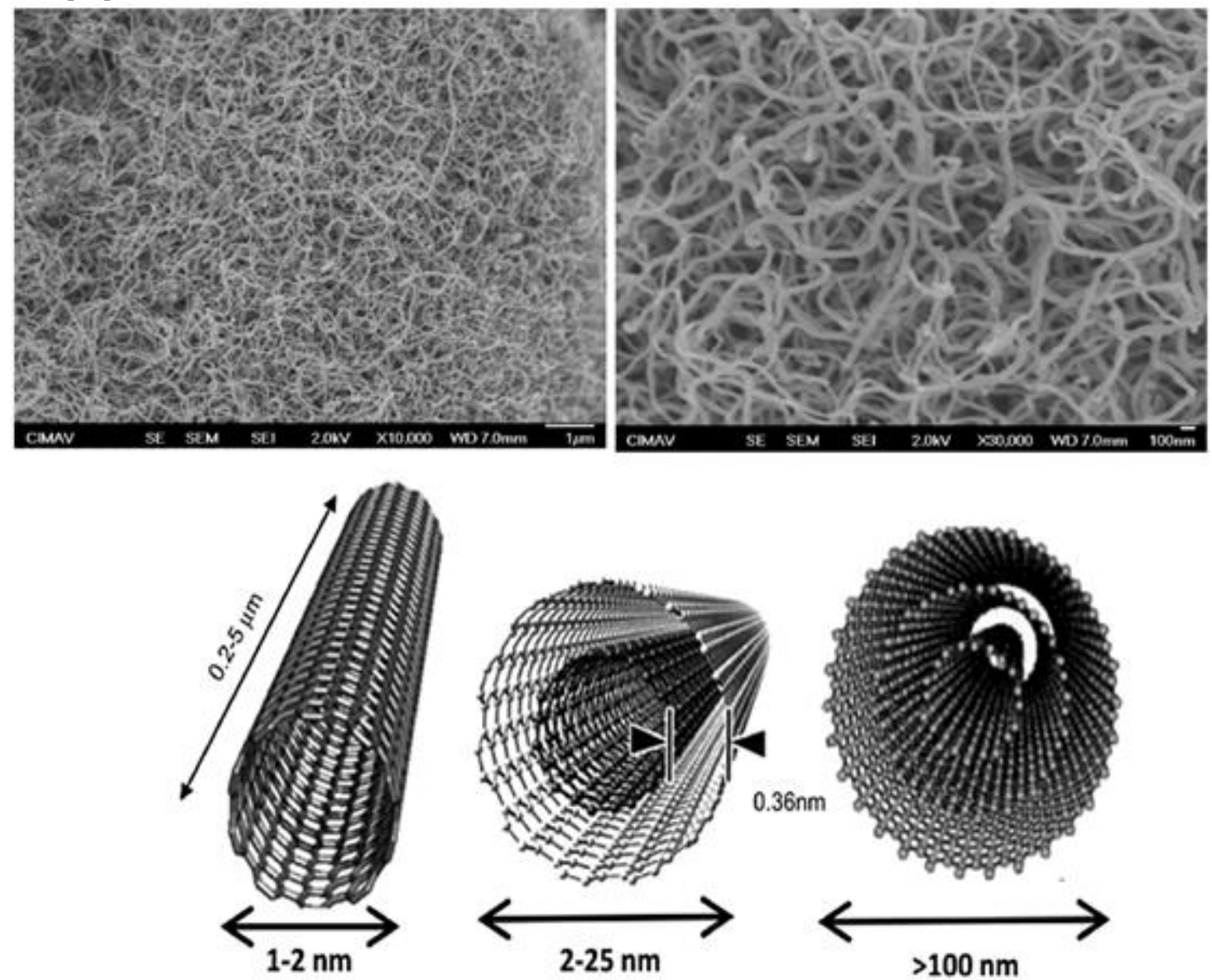

Figure 3. Images of carbon nanotube

Concentration of CNT plays an important role in the tribological result for additive in lubricant. According to a study from Imran, if shows that the friction coefficient was decreased to 0.08 by adding $0.1 \mathrm{wt} \%$ of single walled carbon nanotubes (SWCNT) in the polyalphaolefin (PAO) base lubricant. While for multiwalled carbon nanotubes (MWCNT), the friction coefficient drop to 0.15 when the contact pressure is $0.83 \mathrm{GPa}$.[24]. In a twin-disk tests that apply with a contact stress of $1.1 \mathrm{GPa}$, lubricant added with $0.01 \mathrm{wt} \%$ of SWCNTs promising a highest result of wear resistance [25]. As a conclusion, additive of CNT in lubricant oil poses a reduction in the friction coefficient down to $80 \%$ as the concentration of $0.5 \mathrm{wt} \%$ [24]

\section{CONCLUSION}

In the field of machining, friction coefficient and wear resistance if the main concern of the industries. With the help of additive into base lubricant, both of this problem can be solved. By improving the wear resistance of the tool and the surface of the workpiece, a better surface roughness and longer tool life can be achieved. While reduction in friction coefficient can reduce the power consumption of the machine. Carbon based additive is an organic matter. Therefore, with the aid of carbon based additive will not bring harm to the environment.

\section{ACKNOWLEDGEMENT}

The authors would like to thank UMP for funding this work under an internal grant RDU1803186. 


\section{REFERENCES}

[1] L. Alcaraz, A. López Fernández, I. García-Díaz, and F. A. López, "Preparation and characterization of activated carbons from winemaking wastes and their adsorption of methylene blue," Adsorpt. Sci. Technol., vol. 36, no. 5-6, pp. 1331-1351, 2018.

[2] T. Zhang, W. P. Walawender, L. T. Fan, M. Fan, D. Daugaard, and R. C. Brown, "Preparation of activated carbon from forest and agricultural residues through CO2 activation," Chem. Eng. J., vol. 105, no. 1-2, pp. 53-59, 2004.

[3] Y. Guo, C. Tan, J. Sun, W. Li, J. Zhang, and C. Zhao, "Porous activated carbons derived from waste sugarcane bagasse for CO2 adsorption," Chem. Eng. J., vol. 381, no. July 2019, p. 122736, 2020.

[4] C. F. Chang, C. Y. Chang, and W. T. Tsai, "Effects of burn-off and activation temperature on preparation of activated carbon from corn cob agrowaste by CO2 and steam," J. Colloid Interface Sci., vol. 232, no. 1, pp. 45-49, 2000.

[5] A. Singh, P. Chauhan, and T. G. Mamatha, "A review on tribological performance of lubricants with nanoparticles additives," Mater. Today Proc., no. xxxx, 2019.

[6] P. Lan, L. L. Iaccino, X. Bao, and A. A. Polycarpou, "The effect of lubricant additives on the tribological performance of oil and gas drilling applications up to $200{ }^{\circ} \mathrm{C}$," Tribol. Int., vol. 141, no. July 2019, p. 105896, 2020.

[7] H. Xie et al., "Tribological performances of $\mathrm{SiO} 2$ /graphene combinations as water-based lubricant additives for magnesium alloy rolling," Appl. Surf. Sci., vol. 475, no. October 2018, pp. 847-856, 2019.

[8] X. Li, X. Xu, Y. Zhou, K. R. Lee, and A. Wang, "Insights into friction dependence of carbon nanoparticles as oil-based lubricant additive at amorphous carbon interface," Carbon N. Y., vol. 150, pp. 465-474, 2019.

[9] E. D. Ramón-Raygoza, C. I. Rivera-Solorio, E. Giménez-Torres, D. Maldonado-Cortés, E. Cardenas-Alemán, and R. CuéSampedro, "Development of nanolubricant based on impregnated multilayer graphene for automotive applications: Analysis of tribological properties," Powder Technol., vol. 302, pp. 363-371, 2016.

[10] O. Oginni, K. Singh, G. Oporto, B. Dawson-Andoh, L. McDonald, and E. Sabolsky, "Influence of one-step and two-step KOH activation on activated carbon characteristics," Bioresour. Technol. Reports, vol. 7, no. June, p. 100266, 2019.

[11] I. P. Fulfillment and E. P. Leimkuehler, "Applications of Activated Carbon," no. May, 2010.

[12] S. A. Sajjadi et al., "Efficient mercury removal from wastewater by pistachio wood wastes-derived activated carbon prepared by chemical activation using a novel activating agent," J. Environ. Manage., vol. 223, no. May, pp. 1001-1009, 2018.

[13] B. N. Thomas, S. C. George, and C. O. Shell, "iMedPub Journals Production of Activated Carbon from Natural Sources Abstract Trends in Green Chemistry Preparation of Activated Carbon from Preparation of Activated Carbon from Bamboo Chips Preparation of Aactivated Carbon from Cherry Stones," pp. 1-5, 2015.

[14] M. Li, H. Wang, D. Liu, R. Wang, and Y. Zhu, "RSC Advances Tribological and mechanical properties of self- lubrication epoxy composites fi lled with activated carbon particles containing lubricating oil," RSC Adv., vol. 6, pp. 52596-52603, 2016.

[15] S. Baik, D. Yoon, H. I. Lee, M. K. Ji, L. Gyu-Sun, and L. Young-Ze, "Frictional performances of activated carbon and carbon blacks as lubricant additives," Tribol. Trans., vol. 52, no. 1, pp. 133-137, 2009.

[16] N. M. Nor, L. L. Chung, L. K. Teong, and A. R. Mohamed, "Author â $€^{\mathrm{TM}}$ s personal copy Synthesis of activated carbon from lignocellulosic biomass and its applications in air pollution control - a review."

[17] L. C. A. Oliveira et al., "Preparation of activated carbons from coffee husks utilizing $\mathrm{FeCl} 3$ and $\mathrm{ZnCl} 2$ as activating agents," vol. 165, pp. 87-94, 2009.

[18] Y. Liu, X. Ge, and J. Li, "Graphene lubrication,” Appl. Mater. Today, vol. 20, p. 100662, 2020.

[19] W. Wang, G. Zhang, and G. Xie, "Applied Surface Science Ultralow concentration of graphene oxide nanosheets as oil-based lubricant additives," Appl. Surf. Sci., vol. 498, no. April, p. 143683, 2019.

[20] M. K. A. Ali, H. Xianjun, M. A. A. Abdelkareem, M. Gulzar, and A. H. Elsheikh, "Novel approach of the graphene nanolubricant for energy saving via anti-friction/wear in automobile engines," Tribol. Int., vol. 124, no. April, pp. 209-229, 2018.

[21] F. X. Chen et al., "Three-dimensional graphene nanosheet films towards high performance solid lubricants," Appl. Surf. Sci., vol. 467-468, no. October 2018, pp. 30-36, 2019.

[22] L. Reinert, M. Varenberg, F. Mücklich, and S. Suárez, "Dry friction and wear of self-lubricating carbon-nanotube-containing surfaces," Wear, vol. 406-407, no. March, pp. 33-42, 2018.

[23] H. Pourpasha, S. Zeinali Heris, O. Mahian, and S. Wongwises, "The effect of multi-wall carbon nanotubes/turbine meter oil nanofluid concentration on the thermophysical properties of lubricants," Powder Technol., vol. 367, pp. 133-142, 2020.

[24] I. Ali et al., "Advances in carbon nanomaterials as lubricants modifiers," J. Mol. Liq., vol. 279, pp. 251-266, 2019.

[25] J. A. C. Cornelio, P. A. Cuervo, L. M. Hoyos-Palacio, J. Lara-Romero, and A. Toro, "Tribological properties of carbon nanotubes as lubricant additive in oil and water for a wheel-rail system,” J. Mater. Res. Technol., vol. 5, no. 1, pp. 68-76, 2016.

[26] P. Wiederkehr and T. Siebrecht, "Virtual Machining: Capabilities and Challenges of Process Simulations in the Aerospace Industry," Procedia Manuf., vol. 6, pp. 80-87, 2016.

[27] J. R. S. Prakash, M. Rahman, A. S. Kumar, and S. C. Lim, "Effect of Minimal Quantities of Lubricant in Micro Milling," Initiat. Precis. Eng. Begin. a Millenn., pp. 309-313, 2005.

[28] M. N. Sharif, S. Pervaiz, and I. Deiab, Potential of alternative lubrication strategies for metal cutting processes: a review, vol. 89, no. 5-8. The International Journal of Advanced Manufacturing Technology, 2017. 